\title{
Discussion of paper by J. Zhao, K. Mayumi, C. Creton and T. Narita, entitled 'Rheological properties of tough hydrogels based on an associating polymer with permanent and transient crosslinks: Effects of crosslinking density'
}

Zhao, J.; Mayumi, K.; Creton, C.; Narita, T.; Colby, Ralph; Wilson, James; Hassager, Ole; Ramos, Laurence; Ligoure, Christian; Olmsted, Peter

Total number of authors:

12

Published in:

Journal of Rheology

Link to article, DOI:

$10.1122 / 1.5008885$

Publication date:

2017

Document Version

Peer reviewed version

Link back to DTU Orbit

Citation (APA):

Zhao, J., Mayumi, K., Creton, C., Narita, T., Colby, R., Wilson, J., Hassager, O., Ramos, L., Ligoure, C., Olmsted, P., Creton, C., \& Chen, Q. (2017). Discussion of paper by J. Zhao, K. Mayumi, C. Creton and T. Narita, entitled 'Rheological properties of tough hydrogels based on an associating polymer with permanent and transient crosslinks: Effects of crosslinking density'. Journal of Rheology, 61(6), 1385-1385. https://doi.org/10.1122/1.5008885

\section{General rights}

Copyright and moral rights for the publications made accessible in the public portal are retained by the authors and/or other copyright owners and it is a condition of accessing publications that users recognise and abide by the legal requirements associated with these rights.

- Users may download and print one copy of any publication from the public portal for the purpose of private study or research.

- You may not further distribute the material or use it for any profit-making activity or commercial gain

- You may freely distribute the URL identifying the publication in the public portal 


\author{
Discussion of paper by J. Zhao, K. Mayumi, C. Creton and T. Narita, entitled \\ 'Rheological properties of tough hydrogels based on an associating polymer \\ with permanent and transient crosslinks: Effects of crosslinking density'
}

\title{
Questions JOR - Paper presented by T. Narita
}

\section{Ralph Colby:}

You add salt to maintain constant swelling. Does it affect the lifetime of the stickers and the measured relaxation times? Can you plot these times as a function of salt concentration? Thee is likely an effect since one state of your association equilibrium involves the borate anion,

Answer: This is possible, indeed. The measured relaxation time corresponds to the breaking time of the bond (when the chain relaxation is faster than the bond reassociation time). We do not expect that the bond breaking time depends on the sticker (borate ion) concentration, while the strength of the interaction can be dependent on the ionic strength. We are not able to perform the experiments with the dual crosslink gels at a constant polymer concentration. Some tests with physical gels are under progress.

\section{James Wilson:}

Have you measured $\mathrm{pH}$ before and after adding Borate? Variations around 8 could be important and affect the lifetime of the reversible bonds.

Answer: No, we didn't measure it. But Borax $\left(\mathrm{Na}_{2} \mathrm{~B}_{4} \mathrm{O}_{7}\right)$ is a buffer so we expect $\mathrm{pH}$ to adjust automatically if acid has been removed. We do not expect change in lifetime, but the amount of the crosslinking borate ion which is at equilibrium with non-crosslinking boric acid. But we didn't perform a systematical check.

\section{Ole Hassager:}

In the factoring into strain and time dependence, do you use engineering or true stress?

Answer: Engineering stress.

\section{Laurence Ramos:}

How do you prove the additivity of the stress or modulus? Does it also hold for the loss modulus? Are the two networks independent, or is there a coupling between viscoelasticity of the physical and chemical gel contributions?

Answer: Our definition is the following: one can add the contribution of the chemical crosslinks and that of the physical crosslinks, since we additivity incorporate physical crosslinks to the chemically crosslinked network. The chemical and physical crosslinks contribute to the moduli of the dual crosslink gels additively and independently. We first showed this additivity in 2013 (Narita et al. Macromolecules 2013, 46, 4174 - 4183) by demonstrating that the plateau modulus of the dual crosslink gel scales as a function of the (chemical or physical) crosslinking 
ratio in the same manner as the corresponding chemical gel and physical gel. It holds for the loss modulus: the sticky Rouse mode showing $G^{\prime}=G^{\prime \prime} \sim$ omega $^{\wedge} 0.5$ was observed for the dual crosslink gels when $G_{D}-D_{C}$ are plotted. The two types of crosslinks coexist on the same network of PVA chains, there is no coupling.

(Comment to remove: If I have well understood, you can add the contribution of the two networks, such as $G_{D}=G_{C}+G_{p}$, but still one will affect the other one. Is this correct? In all cases, it seems good to mention accurately how you define this additivity. Evelyne)

\section{Christian Ligoure:}

For a fixed chemical gel, if you vary the number of physical crosslinks, is the stress variation linear in the number of physical X-links? Do you have a direct measurement of these physical crosslinks?

Answer: We think that the answer is yes, though this is difficult to confirm: the number of physical links is probably not linear in Borax concentration especially at high concentrations. The elastic modulus at high frequency corresponds to the closed physical crosslinks, thus it is a direct measurement of the physical crosslinks.

\section{$\underline{\text { Peter Olmsted: }}$}

Could you do three different experiments in order to check the idea of additivity? That is, measure the physical gel only, the chemical gel only, and a physical + chemical gel.

Answer: This comparison has been done by microrheology (Narita et al. Macromolecules 2013, $46,4174-4183$ ), and the moduli of the dual crosslink gels do not correspond to the sum of those of the chemical gel and physical gel. We do not mean that the additivity of the corresponding chemical gel and physical gel. The dual crosslink gel is not an interpenetrating network of the chemical gel and physical gel, the two types of the crosslinks coexist on the same PVA chains. The physical gel flows but the dual crosslink gel does not, thus the dynamics of the physical crosslink can be different.

Constantino Creton pointed out that the chemical gel contribution is mostly low frequency, but the physical is mostly high frequency.

\section{Quan Chen:}

Why does G' saturate at high Borax concentration?

Answer: all the $-\mathrm{OH}$ groups on the polymer are used up.

\section{Christian Ligoure:}

How can you monitor the bond breaking time? And can you play with this value and change it?

Answer: One can macroscopically measure the bond breaking time as a peak of loss modulus if the chain relaxation is fast enough compared to the healing time. For PVA/Borax it seems fixed, you would need to play with a different molecule. 
